\section{SOBRE ALTURAS Y ABISMOS, NERUDA Y MARTÍN ADÁN}

\author{
EVA $M^{a}$ VALERO JUAN
}

\section{Eva $M^{a}$ Valero Juan}

Profesora de Literatura Hispanoamericana en la Universidad de Alicante. Su actividad investigadora se ha centrado en el estudio de la temática urbana en la literatura peruana y, en concreto, en la obra del escritor peruano Julio Ramón Ribeyro. Entre sus publicaciones destacan La ciudad en la obra de Julio Ramón Ribeyro y Lima en la tradición literaria del Perú. De la leyenda urbana a la disolución del mito. Otra línea de investigación a la que ha dedicado diversos trabajos es el estudio de la obra americanista de Rafael Altamira y las relaciones culturales entre España y América durante las primeras décadas del siglo $\mathrm{XX}$, que ha dado como resultado el libro Rafael Altamira y la «reconquista espiritual» de América.
Plantear la relación entre el canto monumental que Pablo Neruda escribió a Machu Picchu, Alturas de Macchu Picchu, y el segundo gran poema dedicado a la ciudad ancestral de los Incas, La mano desasida del peruano Martín Adán, requiere, por mi parte, acudir al germen de la idea. La lanzaba José Carlos Rovira en 1998 cuando en esta universidad celebrábamos el seminario «Neruda con la perspectiva de 25 años», en una conferencia en la que la memoria emotiva se convertía en el mirador ideal para otear la trayectoria del poeta. En aquella intervención titulada «Neruda y nosotros, los de entonces», el entramado de versos y recuerdos daba lugar a la aparición de Machu Picchu, y la vivencia personal hacía emerger la dicotomía entre la trascendencia histórica nerudiana y la visión intimista de Martín Adán frente a las ruinas incaicas. La idea de la comparación entre los dos cantos y sobre todo entre sus respectivas derivaciones poéticas, se encuentra en las siguientes líneas del profesor Rovira, a quien debo la sugerencia de escribir estas páginas que parten de su reflexión inicial:

... allí donde Neruda, hacia 1945, quiso interpretar el espeso silencio de la ciudad incaica, dar la palabra al pasado, llamar a la regeneración americana, encontrarás quizá, pasado el tiempo, más que un paraje mítico, más que una llamada de la historia, el sonido de las cámaras Kodak de los turistas que te acompañan. Es la sensación que ya dejó escrita el poeta peruano Martín Adán en un texto que invertía la trascendencia nerudiana hacia la cotidianidad más definida ${ }^{1}$.

Sobre esa relación entre los dos cantos de Neruda y Martín Adán, cuyos versos se adentran en las nieblas de la ciudadela incaica para interrogar a las piedras con un afán totalizador pero con objetivos distintos, planteo en estas páginas dos escrituras de Machu Picchu que se contraponen y se complementan. Y sin duda es en la búsqueda del significado de esas piedras ancestrales, en la indagación sobre las motivaciones y estímulos literarios de un Machu Picchu que alienta angustias y esperanzas, excitaciones y reflexiones introspectivas, donde ambos poetas encuentran caminos para proyectar sus anhelos intelectuales y vitales.

En este espacio mítico de la historia americana, Neruda y Martín Adán convierten los fragmentos arqueológicos en fragmentos verbales para delinear las ideas que alimentan dos trascendencias poéticas: una (la de Neruda) regenerativa e histórica, y la otra (la de Martín Adán), filosófica y metafísica. Es decir, que si Neruda poetizó las ruinas de los Incas para afirmar y reivindicar una identidad latinoamericana, que debía forjarse en la conexión imprescindible entre pasado, presente y futuro $^{2}$, Martín Adán interpeló a las piedras y su misterio para identificarse con ellas en un proceso de introspección que plantea una búsqueda existencial a través de la plena fusión del poeta con Machu Picchu.

Pero antes de penetrar en la serie de relaciones que se establecen entre Neruda y Martín Adán, creo necesario ubicar a Adán en el escenario cultural y literario del Perú desde los años veinte, tiempo en que la voz de $\mathrm{Ne}$ ruda emergió para traspasar décadas y fronteras, convirtiéndose en figura central de la poesía hispanoamericana del siglo pasado.
1

José Carlos Rovira, «Neruda y nosotros, los de entonces», América sin nombre, «Neruda con la perspectiva de 25 años», $n^{\circ} 1$, Alicante, diciembre de 1999, pp. $43-44$

En una conferencia titulada "Algo sobre mi poesía y mi vida» (Revista Aurora, $\mathrm{n}^{\circ}$ 1, 1954), Neruda reflexiona sobre la significación de su estancia en Machu Picchu en relación con el cambio de signo de su poesía desde España en el corazón: «Pensé muchas cosas a partir de mi visita al Cuzco. Pensé en el antiguo hombre americano. Vi sus luchas enlazadas con las luchas actuales (...) Ahora veía a América entera desde las alturas de Macchu Picchu». Reprod. en "Veía a América entera desde las alturas de Macchu Picchu», Cuadernos de la Fundación Neruda, Año XI no 41, Santiago de Chile, 2000.

Sobre alturas y abismos, Neruda y Martín Adán EVA M ${ }^{a}$ VALERO JUAN 


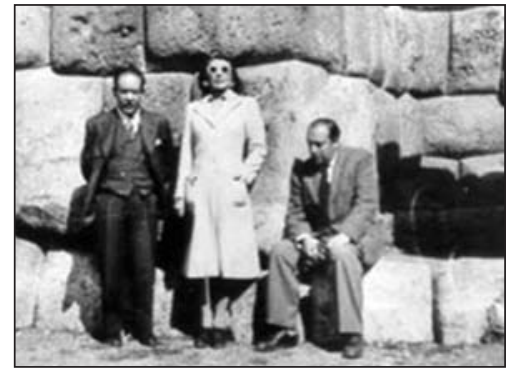

Con Delia en Machu Picchu.

3

Sobre la significación de Martín Adán en este contexto, su profesor Luis Alberto Sánchez lo considera la figura principal de grupo de escritores limeños que a mediados de los años 20 irrumpe bajo el influjo del surrealismo y produce una literatura ironizante y agnóstica: «Bajo apariencia de fe -escribe Sánchez- encerraban un agnosticismo recalcitrante. [...] Martín Adán, en La casa de cartón (1928) inaugura la renovación estética, que acentúa en sus $A n$ tisonetos. La casa de cartón sonríe surrealistamente de la vida provinciana, de la limeña, del balneario, de las viejas criollas, de los tranvías con su contradictoria carga de rutina y fuga. Allegada a la Nueva Revista Peruana, la promoción, de que es Martín gonfarolero, acentúa su perfil agnóstico y oteador de unas emociones más íntimas en Enrique Peña [...], en Emilio von Westphalen [...] en Xavier Abril...». Luis Alberto Sánchez, Panorama de la literatura del Perú, Lima, Milla Batres, 1974, pp. 146-147.

4

Sebastián Salazar Bondy, «Noticias de Martín Adán y La mano desasida", Revista de la Universidad de México, no 1, vol. XVI, México, septiembre de 1961, p. 19.

5

«En cualquier café o bar de Lima es posible encontrar, perdido entre la múltiple fauna urbana, a un hombre descuidado en su traza y su traje (...) Sumido en sí, huidizo y sardónico, encasquetado un sombrero deforme, cubierto por un sobretodo basto, con la

Sobre alturas y abismos, Neruda y Martín Adán

EVA Ma VALERO JUAN gui.

Nacido en Lima en 1908 (sólo con cuatro años de diferencia con respecto a Neruda), Martín Adán sorprendió con su precoz vocación literaria en el panorama de la literatura peruana de los años 20, cuando la reforma universitaria de 1919 clausuraba el anquilosamiento y la caducidad de la generación anterior, y asumía como referentes a los renovadores literarios de comienzos de siglo: Valdelomar y José María Eguren. En el ámbito de esta nueva generación, abanderada por José Carlos Mariátegui y César Vallejo, la rareza de Rafael de la Fuente Benavides (de pseudónimo Martín Adán) comenzaba a alimentar la leyenda que lo convertiría en el poeta maldito, iluminado o místico que se forjó entre soledades y largos silencios. Descendiente de una aristocracia en ruinas, de formación católica y carácter ascético, a la vez cercano a algunas figuras del movimiento aprista y a otras de las juventudes católicas, Adán se convertiría en figura señera de la renovación estética peruana ${ }^{3}$ desde la publicación de La casa de cartón en 1928; novela lírica o poema narrativo cuyo primer fragmento apareció en Amauta ( $\mathrm{n}^{\circ}$ 10, diciembre de 1927), la revista de la nueva generación vanguardista e izquierdista dirigida por Mariáte-

Pero Martín Adán pronto se desvincula del grupo vanguardista y su singularidad se acentúa cuando el tiempo y la soledad lo convierten en poeta bohemio y, como lo calificó Salazar Bondy, en «parroquiano de tabernas» ${ }^{4}$

barba crecida». Sebastián Salazar Bondy, «El conflicto vital de Martín Adán», Mercurio Peruano, Lima, no 388, ago. 1959, pp. 344-346. Cit. en Mirko Laver, Los exilios interiores. Una introducción a Martín Adán, Lima, Mosca Azul, 1983, p. 44.

6

Pablo Neruda, Alberto Hidalgo y Martín Adán, Nuevas piedras para Machu Picchu, Librería-Editorial Juan Mejía Baca, Lima, 1961.

7

Alberto Hidalgo, Patria completa, Librería-Editorial Juan Mejía Baca, Lima, 1960. «descuidado», «huidizo y sardónico» ${ }^{5}$. Tras la ruina y la extinción definitiva de su familia, el poeta comienza su periplo por hoteles de Lima y por hospitales psiquiátricos desde donde escribe poemas en los que el peso existencial va acusando la eterna búsqueda traumática de un yo inencontrable. $\mathrm{Y}$ es en este ámbito vivencial en el que se sitúa su poema a Machu Picchu, La mano desasida, cuyos primeros fragmentos aparecen recogidos en 1961, tras diez años de silencio, en una edición preparada por Juan Mejía Baca titulada Nuevas piedras para Machu Picchu ${ }^{6}$. Con este libro se conmemoraba poéticamente el cincuenta aniversario del descubrimiento de la ciudadela incaica. En él se reúnen fragmentos de los tres principales cantos a las ruinas: $A l$ turas de Macchu Picchu de Neruda, Patria completa del peruano Alberto Hidalgo ${ }^{7}$, y los primeros fragmentos de La mano desasida, que hacían su primera aparición en esta edición compartida.

Por tanto, los primeros trazos poéticos de La mano desasida aparecen junto a fragmentos de aquellas Alturas de Macchu Picchu que Neruda había publicado por primera vez en $1948^{8}$ y dos años después, en 1950, como segundo libro del Canto General ${ }^{9}$. No es de extrañar, pues, la recurrencia a algunas imágenes nerudianas en La mano desasida, aunque sus derivaciones, como veremos, son bien distintas. Porque frente al proceso introspectivo de Martín Adán, que conduce a una humanización de Machu Picchu como imagen del poeta demiurgo, Neruda invoca desde esta ciudad perdida al hombre castigado por la historia que yace sepultado en el fondo de la tierra, para, finalmente, en los últimos versos, convocar a la esperanza del hombre futuro:

Pablo Neruda, Alturas de Macchu Picchu, Santiago, Ediciones Librería Neira, 1948.

9

Pablo Neruda, Canto general, México, Talleres Gráficos de la Nación, 1950.

10

Pablo Neruda, Alturas de Macchu Picchu, Canto general, en Obras completas I, Hernán Loyola (ed.), Barcelona, Galaxia Gutenberg, 1999, p. 447. Para las siguientes citas de Alturas... sigo esta edición e indico la página entre paréntesis.
Dadme el silencio, el agua, la esperanza.
Dadme la lucha, el hierro, los volcanes.
Apegadme los cuerpos como imanes.
Acudid a mis venas y a mi boca.
Hablad por mis palabras y mi sangre $^{10}$.

Sin duda, la dirección poética de Martín Adán en La mano desasida difería sustancialmente de la adoptada por Neruda: desde una visión narcisista, el peruano no se propuso convocar al hombre desvalido para redimirle, sino convocarse a sí mismo, con sus dudas y sus certezas, a través de la invocación a la piedra: «¿Qué palabra simple y precisa inventaré 
/ para hablarte Mi Piedra?», se pregunta. Con esta invocación, Machu Picchu se convierte en símbolo principal del soliloquio del poeta, y en el gran escenario desde donde Adán proyecta una espiral de preguntas y contradicciones sobre la muerte, la Creación, Dios, o el propio yo identificado con las ruinas.

En la década de silencio que transcurre desde la publicación de su último poemario (Travesía de extramares, 1951), la gestación de La mano desasida va acompañada de una especie de poema prólogo titulado Escrito a ciegas, donde esa temática existencial ya había comenzado a manifestarse en la suma de opuestos y contradicciones que caracterizará su particular canto a Machu Picchu, en versos como:

No, no soy el que busca

el poema, ni siquiera la vida...

Soy un animal acosado por su ser

que es una verdad y una mentira ${ }^{11}$.

Tras la publicación de los primeros fragmentos en 1961, La mano desasida tuvo una segunda publicación en 1964 que incluía nuevos fragmentos: fue el propio editor, Mejía Baca, quien transcribió los textos que Martín Adán le iba entregando en papeles sueltos. La publicación de la versión completa no vería la luz hasta $1980^{12}$, con casi trescientas páginas y unos ocho mil versos en los que un abismo de obsesiones dan la dimensión del poeta inmerso en el propio ser de la materia, sumido en un diálogo intenso con las piedras en busca de un yo enmascarado desde el comienzo por el pseudónimo y su ironía.

El pseudónimo nos conduce al origen, punto inicial en el que convergen Neruda y Martín Adán. Si Neftalí Reyes inauguró su proyecto poético con la invención de un nombre (Pablo Neruda), Rafael de la Fuente Benavides impregnó de ironía su nacimiento literario con la creación de Martín Adán que, como el nombre Pablo Neruda, no son tanto pseudónimos como las máscaras que contienen la orientación autobiográfica de sus respectivas obras. Con la máscara ambos nacen a la poesía, dan comienzo a ese yo ficticio que, en el caso de Neruda, Alain Sicard ha desentrañado en su artículo «El rostro como máscara». Sus palabras nos dan la exacta medida del yo poético en el Canto general: «no el yo de la existencia biográfica -escribe Si- card-, sino ese yo proteico e imaginario capaz de vivir en la escritura todas las vidas de la historia. Ser Cuauhtémoc y Bolívar, Las Casas y Recabarren, ser el pueblo chileno en la infinita multitud de sus nombres anónimos es lo mismo que ser matorral y ciruelo, alerce y trigo» ${ }^{13}$. En el caso de Martín Adán, la máscara es doble y profundamente irónica, dado que concilia a Darwin (martín significa mono en Lima) con el primer hombre del Génesis, marcando el origen herético de su búsqueda incansable del yo entre máscaras que se contraponen ${ }^{14}$.

Partiendo de ese momento originario en que Neruda y Adán inauguran su obra literaria y estrenan el nombre que la acompaña, me detengo en estos comienzos que se remontan a los años veinte para trazar la relación entre ambos a través de varias estaciones en el camino de ascenso a Machu Picchu. Una ascensión en dos cantos que convergen en el tono épico y profético de la interpelación a la montaña sagrada y en un posible proceso intertextual de imágenes recurrentes que, sin embargo, se distancian en la significación última del autorretrato de Neruda y Adán en las cumbres de la ciudad andina.

\section{$1^{a}$ ESTACIÓN: DE LA CIUDAD MO- DERNA A LA CIUDAD ANCESTRAL}

Reiterar en términos generales la evolución que Neruda desarrolla en las tres Residencias desde un surrealismo personal de fondo metafísico hacia la conciencia histórica que deviene en actitud política y social desde España en el corazón y posteriormente en el Canto general, es imprescindible para plantear una comparación con la trayectoria de la poesía de Martín Adán. Casi podríamos decir que, en síntesis, se trata de una evolución inversa: Martín Adán parte de un vanguardismo tardío a finales de los años veinte, a través del cual trata de poetizar las sensaciones de extrañamiento que le produce la transformación vertiginosa de la ciudad de Lima; un vanguardismo efímero que no va más allá de los primeros poemas y de La casa de cartón (1928), donde la crítica social penetra a través de la ironía y la nostalgia. Sin embargo, a partir de los años treinta, la poesía de Adán cierra la ventana al mundo exterior y clausura lo social
11

Martín Adán, Escrito a ciegas, en la antología titulada El más hermoso crepúsculo del mundo lantología), Jorge Aguilar Mora (ed.), México, Fondo de Cultura Económica, 1992, p. 196. Para las citas de La mano desasida sigo esta antología e indico la página entre paréntesis.

12

El libro aparece publicado en la edición de Martín Adán, Obra poética, Lima, Edubanco, 1980.

13

Alain Sicard, «El rostro como máscara: autobiografía e historia en la obra de Pablo Neruda", en Ángel Flores (compág.), Nuevas aproximaciones a Pablo Neruda, México, F.C.E., 1987, p. 29

14

A este respecto, José Carlos Mariátegui escribió en una nota a la primera edición de un fragmento de La casa de cartón en Amauta: «Su nombre, según él, reconcilia el Génesis con la teoría darwiniana. Le hemos objetado privadamente, que Martín llaman los monos [sic] sólo en Lima y el Barranco y que Adán es patronímico inverosímil. Mas si Martín Adán se llama así realmente, no cabe duda que se trata de un humorista y hereje de nacimiento». Amauta, Año II, n 10, diciembre de 1927, Lima, p. 16.

Sobre alturas y abismos, Neruda y Martín Adán EVA Ma VALERO JUAN 


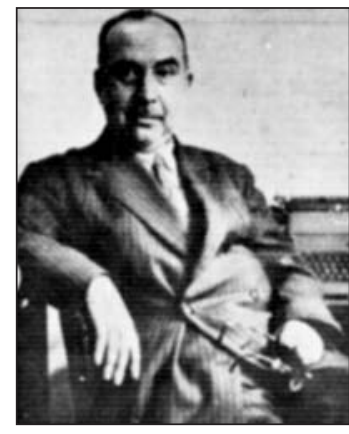

Martín Adán.

15

Pablo Neruda, «Sobre una poesía sin pureza», en Caballo verde para la poesía, $\mathrm{n}^{\circ}$ 1, Madrid, Octubre 1935. Madrid / Nendeln-Liechtenstein, Turner / Kraus Reprint, 1974, p. 5.
Sobre alturas y abismos, Neruda y Martín Adán EVA Ma VALERO JUAN para forjar un hermetismo que penetra hacia dentro, conduciendo su creación hacia esa trascendencia existencial en la que La mano desasida es sin duda el poema cardinal.

El resultado de ambas evoluciones poéticas contiene la diferencia sustancial entre $A l$ turas de Macchu Picchu y La mano desasida: frente al encuentro del «otro» por Neruda, que emerge de las soledades del yo y la materia desde las Residencias, la búsqueda del "yo" por Adán como centro del mundo y de la poesía, cuando el contenido social de sus primeros poemas ya no tiene cabida en su obra. Y si he dado a esta Primera Estación el título «De la ciudad moderna a la ciudad ancestral» es porque creo que en Alturas de Macchu Picchu la presencia del tránsito desde la urbe hasta Machu Picchu sintetiza en buena medida esa evolución del poeta desde los abismos del yo y de la muerte hacia el reencuentro con el hombre y su historia; y porque del mismo modo considero que la evolución de la poesía de Martín Adán desde la estética vanguardista a la poesía existencialista puede visualizarse a través de esas dos imágenes, de la ciudad moderna de sus primeros escritos, a la ciudad ancestral de los Incas en La mano desasida.

Comencemos con Neruda. Ya en 1935, en «Sobre una poesía sin pureza» (el famoso prólogo a Caballo verde para la poesía), el poeta había escrito sobre la necesidad de poetizar

el contacto del hombre y de la tierra como una lección para el torturado poeta lírico. Las superficies usadas, el gasto que las manos han inflingido a las cosas, la atmósfera a menudo trágica y siempre patética de estos objetos, infunde una especie de atracción no despreciable hacia la realidad del mundo. La confusa impureza de los seres humanos se percibe en ellos, la agrupación, uso y desuso de los materiales, las huellas del pie y los dedos, la constancia de una atmósfera humana inundando las cosas desde lo interno y lo externo ${ }^{15}$.

Tras esas huellas del hombre Neruda emprende su ascenso poético a la montaña sagrada de los Incas, donde la atmósfera humana, en ocasiones trágica y patética, surge de lo interno, de las entrañas de lo terrestre, para inundar lo externo de esas piedras que guardan la pátina indeleble del tiempo y la vida. Esas huellas profundamente humanas son las que Neruda persigue entre los huecos de las ruinas en este segundo libro del Canto general, donde apuesta por una poesía que se interne en la tragedia del hombre oprimido para invitarle a subir hasta la raíz de la piedra; una poesía que en definitiva descubra al hombre desnudo y auténtico a través de una visión poética de la historia que más que regresiva es anunciadora de esperanzas futuras. Esta apuesta de autenticidad encuentra en Machu Picchu el símbolo idóneo para lanzar el canto profético y utópico a la sociedad latinoamericana. Y Neruda consigue potenciar la significación del símbolo de las ruinas incásicas por oposición con las primeras imágenes del yo poético atrapado en las redes de la ciudad:
Del aire al aire, como una red vacía
iba yo entre las calles y la atmósfera (...)
Cuántas veces en las calles de invierno de una ciudad o en un autobús o un barco en el crepúsculo, o en la soledad más espesa (...)
me quise detener a buscar la eterna veta insondable que antes toqué en la piedra o en el relámpago que el
[beso / desprendía.
(págs. 434-435)

Esta decepción hace emerger en el poema la imagen de la ciudad enmascarada de la modernidad:

No pude asir sino un racimo de rostros o de máscaras / [precipitadas (...)

Qué era el hombre? En qué parte de su conversación /

[abierta

entre los almacenes y los silbidos, en cuál de sus

[movimientos metálicos

vivía lo indestructible, lo imperecedero, la vida? (pág. 436)

La imposibilidad de hallar en el espacio de la ciudad moderna esa autenticidad que $\mathrm{Ne}$ ruda había identificado con las piedras de Machu Picchu desde su visita en 1943 supone además el desencuentro con la inspiración poética (simbolizada en la imagen de la mano) en ese espacio alienante: «No tuve sitio donde descansar la mano (...)» (pág. 436). Tras esa constatación, Neruda orienta el camino de su poema desde la urbe moderna hacia la ciudad ancestral de los Incas, cuando un breve recorrido por el «lodo del suburbio», «las calles espesas» y la pequeña muerte de cada día en la ciudad concluye en la cuarta parte del canto con el anuncio del viaje a Machu Picchu: 
«Entonces fui por calle y calle y río y río / y ciudad y ciudad y cama y cama / y atravesó el desierto mi máscara salobre...» (pág. 437). El ascenso a Machu Picchu, como acto iniciático, representa el renacimiento del poeta y su máscara, que termina esta sección «rodando, muriendo de la propia muerte».

A partir de este momento, las «abandonadas torres incásicas» ${ }^{16}$ realzan su estatura cuando el poeta las convierte en ciudad de piedra, morada de lo auténtico y de lo primigenio no corrompido:

Entonces en la escala de la tierra he subido entre la atroz maraña de las selvas perdidas hasta ti, Macchu Picchu.

Alta ciudad de piedras escalares

por fin morada del que lo terrestre

no escondió en las dormidas vestiduras (...)

Madre de piedra, espuma de los cóndores,

alto arrecife de la aurora humana (...)

Esa fue la morada, éste es el sitio. (págs. 438-439)

Machu Picchu, la ciudad-santuario, aparece en definitiva como símbolo de lo eterno capaz de acoger y proyectar en el verso el canto épico a la solidaridad que Neruda construyó a través de la magnificación de este espacio mítico:

la ciudad como un vaso se levantó en las manos de todos, vivos, muertos, callados, sostenidos de tanta muerte, un muro, de tanta vida un golpe de pétalos de piedra: la rosa permanente, la morada: este arrecife andino de colonias glaciales. (pág. 440)

Esta oposición entre la urbe moderna y la ciudad ancestral es también muy significativa para comprender la evolución poética de Martín Adán: partiendo, al igual que Neruda, del choque que significa la imagen de la ciudad moderna como lugar de falsas representaciones frente a la autenticidad de las ruinas del pasado, Adán transita desde un vanguardismo de contenido social y representaciones urbanas, hacia el espacio metafísico y filosófico de la ciudad en ruinas en La mano desasida. Por tanto, retoma la representación de Machu Picchu como morada de lo auténtico, pero en su caso la antropomorfización de este espacio no remite a la colectividad del hombre (como en Neruda) sino a la individualidad del poeta identificado con las ruinas:
¡Deidad de la circunstancia

eres Yo mismo!

Eres la duda cierta y la misma vida, eres lo humano y macizo de cielo y nube, eres lo infinito que se está,

y eres la palabra que huye. (pág. 233)

Estas imágenes de Machu Picchu contrastan con la representación alienante de la urbe en sus primeros escritos, sobre todo en $\mathrm{La}$ casa de cartón (1928), donde Adán, a través del surrealismo, había penetrado en una realidad limeña desconocida en la literatura peruana y había revelado la imagen de la ciudad como espejismo de la realidad:

Lima, la sucia Lima, caballista, comercial, deportiva, nacionalista, tan seria [...] خÁrboles...? -los farolestroncos de arbustos que la luz tuerce y la sombra hace verdes. A las seis de la mañana, a las seis de la tarde, son los faroles lo más vegetal del mundo, de una manera analítica, sintética, científica, pasiva, determinante, botánica, simplísima -los troncos sostienen al extremo superior campanas de cristal que encierran flores amarillas. (pág. 333)17.

Ante la falacia de esta Lima transformada de la que Adán fue testigo privilegiado, el tránsito hacia el Machu Picchu de La mano desasida viene precedido, como ya he apuntado, por ese poema titulado Escrito a ciegas en el que el poeta se pregunta: «¿Quién soy? Soy mi qué, /inefable e innumerable» (pág. 196). La búsqueda ha comenzado en el seno de la ciudad, y por eso en Escrito a ciegas la secuencia de preguntas empieza aludiendo a esa imagen de la urbe inmunda que había utilizado como primer referente de su literatura: «¿Sabes de la ciudad tanta, / que no parece ciudad, / sino cadáver disgregado, / innumerable e infinitesimal» (pág. 200). Frente a esa imagen, Adán funde el espacio de Machu Picchu con el yo íntimo en La mano desasida; se identifica con su alma de piedra de manera que Machu Picchu será a partir de ahora el «pobre rostro mío, mi alma de piedra, / exacta y rompidísima, / innumerable e idéntica» (pág. 203). Es decir, el alma del poeta sigue siendo innumerable (desde la creación del pseudónimo), pero idéntica a la piedra, y exacta.

La imagen de la exactitud de Machu Picchu nos plantea otra posibilidad de juego intertextual, dado que ya Neruda la había utili-

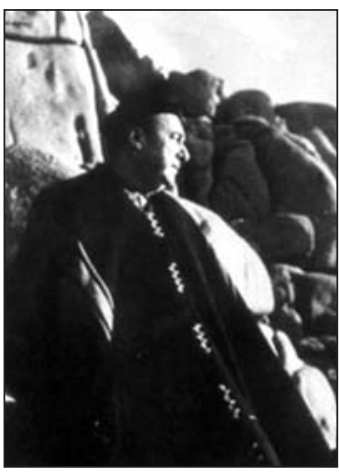

Neruda en Machu Picchu.

16

Así denomina Neruda a Machu Picchu en la conferencia titulada «Algo sobre mi poesía y mi vida», en 1954 (Revista Aurora, no 1).

17

Martín Adán, La casa de cartón, en El más hermoso crepúsculo del mundo, ed cit., p. 333. La cursiva es mía.
Sobre alturas y abismos,

Neruda y Martín Adán

EVA Ma VALERO JUAN 


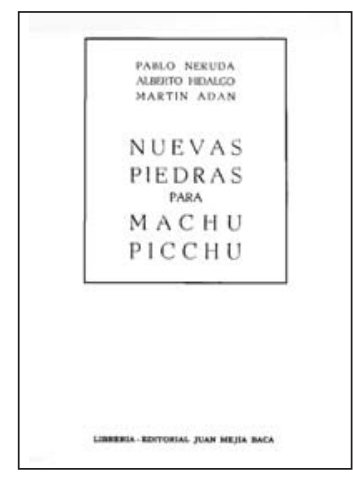

Nuevas piedras para Machu Picchu.

18

A través esta imagen, Neruda identifica la solidaridad humana con la perfecta armonía de las piedras. Así lo manifiesta el poeta cuando escribe: "Macchu Picchu se reveló ante mí como el perdurar de la razón por encima del delirio, y la ausencia de sus habitantes, de sus creadores, el misterio de su origen y de silenciosa tenacidad, desencadenaron para mí la lección del orden, que el hombre puede establecer a través de los siglos con su voluntad solidaria». Pablo Neruda, «Nuestra América es vasta e intrincada», presentación del libro Civilización andina de Roberto Magni y Enrique Guidoni. En Cuadernos de la Fundación $\mathrm{Ne}$ ruda, Año XI, n 41, Santiago de Chile, 2000.
Sobre alturas y abismos, Neruda y Martín Adán EVA Ma VALERO JUAN zado en el verso «cuando la mano de color de arcilla / se convirtió en arcilla..., / quedó la exactitud enarbolada» (pág. 440), para referirse a la perfección de las ruinas tras la caída de sus moradores y a la armonía de sus piedras como imagen de la armonía de los hombres que la construyeron ${ }^{18}$. En La mano desasida Adán insiste en esta idea del orden, la exactitud y la geometría de las piedras en su arquitectura, que le lleva a considerar a Machu Picchu como «dios al tacto y de la geometría», como «iExactitud sublime!», pero la significación de la idea es, de nuevo, sustancialmente diferente a la de Neruda: Adán identifica esa exactitud de la ciudad de piedra con su propia alma, y no con la «voluntad solidaria» del hombre, por ejemplo en versos como:

¡Ser exacto, humanísimo

y trascendental, ampárame!

$¡$ Machu Picchu, mi cuerpo,

estáteme! (pág. 245)

En suma, el viaje de Neruda y Adán desde la urbe hasta la ciudad-santuario nos ha mostrado una identificación de imágenes que en ambos responden a la oposición entre lo genuino y lo inauténtico, pero que sin embargo derivan en dos trascendencias distintas, la colectiva de Neruda frente a la individual de Adán, y que son muy significativas en cuanto a la evolución que ambos experimentan en sus obras desde los orígenes de su poesía hasta la escritura de Alturas de Macchu Picchu y La mano desasida.

\section{$2^{a}$ ESTACIÓN: LA MANO TURBULENTA Y DULCE, LA MANO DESASIDA}

Otra imagen simbólica que de manera insistente recorre Alturas de Macchu Picchu y que Martín Adán erige en símbolo central desde el mismo título de la obra es la imagen de la mano. En términos generales, más allá de significados específicos que marcan los matices de diferenciación, creo que en ambos poemas la significación central del símbolo remite a la mano del poeta como vehículo de conocimiento y de creación. Pero ante todo, quiero plantear la hipótesis de un posible juego intertextual desarrollado por Martín Adán en La mano desasida, título en el que quizás podemos visualizar la imagen que Neruda ha- bía construido en Alturas de Macchu Picchu en los siguientes versos:

Él sostuvo una mano que cayó de repente desde la altura hasta el final del tiempo. (pág. 440)

Sobre esta imagen de la mano desasida, de esa mano creadora del poeta que desde la altura cayó en busca del hombre antiguo, $\mathrm{Ne}$ ruda insiste en otros versos como: «hundí la mano turbulenta y dulce / en lo más genital de lo terrestre» (pág. 434). La imagen reaparece en los versos de Martín Adán, pero en ellos la resemantización es evidente, cuando en primer lugar el símbolo se refiere a la mano de Dios:

Porque la soledad no le bastaba, la del Principio. Él buscó su mano y el poeta dice que fue nunca (pág. 210)

Y en segundo lugar, cuando Adán se convierte en el poeta demiurgo que hunde la mano en la raíz de sí mismo para identificarse con Machu Picchu como imagen de un dios humanizado que creó el mundo a través de la palabra:

¡Este sentirse uno Dios ante la propia conciencia y ante la propia herejía...

¡Este haberte hecho un humano como yo (...)

¡Este tu estar a mi medida humana, sin suelo, sin habitantes y con sola tu agonía!

(pág. 224)

Más tarde, en los versos de Adán reaparece la visión nerudiana de la caída desde la altura hasta el abismo a través de la acción de la mano:

Si tu mano toca,

huye la Muerte y te mata la Vida.

Cáete, si eres, Machu Picchu,

cáete conmigo. Te lo digo: no sigas

presidiendo las cosas y los cielos, con tus piedras

[caedizas (pág. 234)

«Vivir es tacto», nos dice Martín Adán en el poema, asumiendo el significado del símbolo de la mano como instrumento de pensamiento y vida, y concibiendo la escritura como vehículo principal para la aprehensión del mundo. Este significado se evidencia en otros versos como «No te asustes, Mi Genio, / no 
te asustes, Mi Gramática, / no te asustes, Mi Mano» (pág. 246), en los que el autorretrato de esa mano desasida como símbolo del poeta que busca un asidero en la piedra, Dios, o la poesía, orienta la escritura del yo inefable:

Pero Machu Picchu, amigo,

no es otra cosa que un verso, algo yo, de mi figura,

algo que yo estoy haciendo.

Si yo me aparto de mi obra,

ya no soy porque no creo.

¡Sí, mi cuerpo es esta mano,

esta con que a ti me atengo,

con la que te hice hace siglos

en un instante del Tiempo (pág. 237)

¿Eres verdaderamente yo,

o la Divinidad, o la Poesía? (pág. 217)

Por tanto, partiendo del significado común del símbolo que Neruda utilizó en Alturas de Macchu Picchu, de nuevo Adán lo deriva hacia la significación solipsista de su canto. De este modo, retoma y transforma la imagen de la mano que en Alturas de Macchu Picchu es central para el proceso de conversión del yo poético en redentor de la colectividad sin voz:

A través de la noche de piedra, déjame hundir la mano y deja que en mí palpite, como un ave mil años

[prisionera,

el viejo corazón del olvidado! (pág. 445)

En otros versos de los dos cantos, la simbología de la mano como vehículo del saber se desvanece, cuando Neruda y Adán piden la mano para poder alcanzar el objetivo de sus respectivos proyectos poéticos, planteando otra posibilidad de intertextualidad. Si Neruda solicita la mano al hombre antiguo para proyectar la conciencia histórica que, como ha escrito José Carlos Rovira, «genera el principio de actuación poética, la praxis hacia la que el poema llama a la colectividad, la praxis para un renacimiento, para una regeneración, para el hombre nuevo» ${ }^{19}$, en versos como

sube a nacer conmigo, hermano.

Dame la mano desde la profunda

zona de tu dolor diseminado. (pág. 446),

Martín Adán reclama la mano de Machu Picchu para acercarse a las alturas de lo inefa- ble y fundirse con la piedra, utilizando el mismo sintagma pero distanciándose nuevamente de Neruda en la finalidad existencial de su canto:

Sí, tú, dame la mano,

llévame arriba, llévame al ansia,

llévame a donde no sé si mi pie existe

ni cuando el límite acaba.

Déjame ser como tú eres

déjame ser de piedra y labra.

\section{$3^{a}$ Y ÚLTIMA ESTACIÓN: SOBRE AL- TURAS Y ABISMOS}

Desde la profundidad hasta las alturas, Neruda se propuso «subir todos los escalones del aire hasta el vacío» (pág. 444), hasta llegar a esas alturas desde las que vio a América entera. Martín Adán, sin embargo, se desesperó en su búsqueda del camino: «¿Por dónde se sube al abismo?» (pág. 228), se pregunta. Pero sus abismos no eran los abismos de la tierra, no eran las entrañas ni los orígenes de la América sumergida de Neruda, sino las profundidades del yo enfrentado a sí mismo en ese espejo que encontró en la ciudad perdida:

¿Dónde estás, que no me encuentro,

Machu Picchu maldito? (pág. 219)

Y en lo hondo de todo, y en la sima de arriba

estamos tú y yo. (pág. 233)

En La mano desasida Machu Picchu es el espacio de lo genuino que comienza también a ser invadido por ese mundo que Adán desprecia y satiriza, representado por el turista, «con su kodak y su maleta»; imagen recurrente con la que el poeta incursiona en ese espacio de cotidianidad que, como apuntó José Carlos Rovira, invierte la visión histórica de las ruinas de Neruda hacia otras derivaciones en las que he tratado de penetrar a lo largo de estas páginas. Estas derivaciones surgen, como hemos visto, de la resemantización de algunas imágenes que Adán podría haber retomado del primer canto a «la ciudad perdida y añorada» de Pablo Neruda. Y que, en cualquier caso, son imprescindibles para analizar las relaciones que se establecen entre las dos visiones poéticas del Machu Picchu de Neruda y Martín Adán.

En definitiva, ambos escritores parten de la conversión de su propia vida en objeto de su
José Carlos Rovira, Para leer a Neruda, Madrid, Palas Atenea, 1991, p. 112. 
obra poética, pero el contraste es evidente: los versos de Neruda contienen un proceso de purificación espiritual que convierte al poeta en redentor del hombre, $\mathrm{y}$ al poema en canto épico a la solidaridad y al futuro; por el contrario, en los versos del peruano surge la imagen del poeta anti-héroe y marginal que, de una forma descarnada, muestra las profundas fisuras que horadan una poesía impregnada del dolor del poeta ante el mundo, y que en la arquitectura de la piedra se magnifican a través de la identificación del yo disgregado con la piedra innumerable.

A través de tres estaciones hemos llegado a estas alturas que Neruda y Adán escalan por caminos que se bifurcan: Martín Adán asciende a Machu Picchu como quien desciende al abismo del yo; Neruda protagoniza un descenso a los orígenes, a los abismos de una tierra ancestral, para desde allí, comenzar el ascenso a las «Alturas» de la montaña sagrada y convertirse en cantor de América Latina y su historia. Sobre alturas y abismos, entre las ruinas de la ciudad de piedra, Neruda y Martín Adán reconstruyen Machu Picchu para construir, en definitiva, dos imágenes del yo que traducen un cambio sustancial en la visión poética de la última ciudadela de los Incas: de la concepción mítica y profética de la historia hacia la poesía metafísica del poeta disgregado y roto entre las ruinas del mundo. 